\title{
Memorial functional foods: a new concept from Bavi tribe
}

\author{
Ehsan Amiri Ardekani ${ }^{1,2}$, Hossein Askari ${ }^{1}$ and Abdolali Mohagheghzadeh ${ }^{1,3^{*}}$ (i)
}

\begin{abstract}
The use of functional foods (FFs) for maintaining health and preventing or treating illnesses_-in recent years_-has been dramatically increased in the literature. There are available valuable examples of FFs in ethno medicine from different tribes. Ethnic FFs can be valuable resources for developing FFs science, e.g., introducing memorial FFs as an interdisciplinary ethnopharmacological concept. In this paper, ethnic FFs from Bavi tribe (Kohgiluyeh va Boyerahmad province of Iran) have been studied, and their medical potentials are reported. Data gathering was done by interview with Bavi tribe local healers using a questionnaire. Plant materials were collected and identified, and Bavi FFs were prepared according to local procedures. Information of 21 Bavi tribe FFs was collected which are including 20 different plant species.The results showed that most FFs are used to treat chronic diseases including kidney problems like kidney stones, liver disease, neurological complaints, and Gl ulcers and are used as lactogogue, while lesser FFs are used to treat acute diseases and symptoms (43\%), including nausea and vomiting, common cold, diarrhea, sore throat, and allergy. Most FFs of Bavi tribe are prepared using aromatic plants (75\%) responsible for aroma in the final FF. Probably, aromatic FFs increase patient acceptance, without mimicking unpleasant memory of drug recommendation. Plants that are used in FF are mostly perennial (80\%) and wild growing (80\%), indicating continuous contact of natives and so having memory with such habitant herbals. Treating diseases by homemade FFs which are prepared by well-known aromatic herbals is a routine procedure among natives like the Bavi tribe. Such easily made FFs with well-known taste and flavors which may change the patient's mood should be studied in a new approach, "memorial FFs", as a novel opportunity for healthcare and curing.
\end{abstract}

Keywords: Bavi tribe, Functional foods, Ethnic foods, Memorial functional foods, Food-cultural studies

\section{Introduction}

Ethno medicine contains knowledge, skills, and activities which are based on behavior, culture, and experience of natives. Such knowledge is used to treat various physical and mental ailments. Traditional Persian medicine (TPM) divides practical medicine into "Hifze Sehat" (hygiene) and "Moalejat" (therapeutic medicine) branches [1]. Due to the close relation of traditional and ethnic phytopharmaceuticals, they have long been valuable guides for modern research and development of pharmaceutics [2]. Today, globalization and mixing of cultures has gradually faded differentiated ethnic groups features, such as

\footnotetext{
* Correspondence: mohaghegh@sums.ac.ir

'Department of Phytopharmaceuticals (Traditional Pharmacy), Faculty of

Pharmacy, Shiraz University of Medical Sciences, P. O. Box 1583, 71345

Karafarin Avenue, Shiraz, Iran

${ }^{3}$ Pharmaceutical Sciences Research Center, Shiraz University of Medical

Sciences, Shiraz, Iran

Full list of author information is available at the end of the article
}

languages and traditions; as a result, rules and ethnic medical knowledge of natives barely have remained alive. Moreover, due to changes in the awareness of indigenous people, and increasing impact of globalization, indigenous knowledge is constantly declining [2]. In many parts of the world, especially in isolated places and areas where physicians and pharmacists are not available, people commonly use their ancestors' home remedies and ethno medicine. In fact, what is transmitted from generation to generation is not only information but also indigenous memories and beliefs. According to Jennings, family is the most important source of knowledge in the community [3]. As a result, local medications and functional food (FF) procedures have been transmitted from parents to children during the centuries, and in the present age, as a result of gape between generations, there is no guarantee for continuation of this transition [2].

(c) The Author(s). 2020 Open Access This article is distributed under the terms of the Creative Commons Attribution 4.0 International License (http://creativecommons.org/licenses/by/4.0/), which permits unrestricted use, distribution, and reproduction in any medium, provided you give appropriate credit to the original author(s) and the source, provide a link to the Creative Commons license, and indicate if changes were made. The Creative Commons Public Domain Dedication waiver (http://creativecommons.org/publicdomain/zero/1.0/) applies to the data made available in this article, unless otherwise stated. 


\section{Native FFs}

As a definition, "food provides energy and building materials for countless substances that are essential for the growth and survival of every human being" [4]. Diplock notes that food can be considered as a pharmaceutical, if it has beneficial effects on the functions of the body, in order to create effects beyond nutritional effects such as health and prevention of illness [5]. This concept has been expressed by Hippocrates thousands of years ago as: "Let food be thy medicine and medicine be thy food." This means that food should have pharmacological effects, and medicine should have food criteria. The term "FF" was first introduced by the Japanese in the mid1980s, meaning processed foods for medicinal and health purposes. Furthermore, FF is described as a kind of food that is nutritional and stimulates or exerts a specific activity in the body [6]. Many epidemiological researchers, clinical assessors, and biochemists of modern foods have considered the link between food and health. For instance, if the proper diet is consumed, it will regulate the physiology of the body. Studies on diet patterns indicate the importance of fruit and vegetable consuming for a healthy diet [7]. In fact, using fruit and vegetables can alleviate depression and anxiety and cause better mood for patients [8]. Vegetarian foods, in addition to providing daily energy to the body, can also prevent diseases and promote health due to their phytochemicals [9-11]. In fact, phytochemical compounds present in medicinal plants which are used in foods improve the health of individuals, help cure chronic diseases, and prevent cancer and cardiovascular and neurological diseases [12]. All in all, as it is reported in the literature, the minimum criteria for FF would be unified as the following [9-11]:

- The product used by the patient should be in the form of food, not in the form of pills, capsules, syrups, and other dosage forms.

- The food should be included as a part of daily diet.

- Consumption of the product should affect certain processes in the body that includes impact on the mechanisms of defense, prevention, and treatment of certain diseases, adjustment of physical and mental conditions, and delay in the aging process.

Nowadays, global tendency to FFs has been increased due to reasons such as importance of FFs in preventing diseases [13]; potential of FFs for increasing life expectancy [14]; increasing healthcare costs [15]; and prevalence of chronic diseases, such as diabetes, obesity, cardiovascular disease, and even cancer [14]. The abovementioned factors have made FF market more prosperous than ever, and it is estimated to reach $\$ 192$ billion by 2020 [16]. Unfortunately, it seems that a small share of the market is intended to be devoted to ethnic FFs. In spite of the fact that nutraceuticals and FFs are new subjects in medicine, there are examples of FFs in folk medicine and TPM [1]. The importance of FFs in TPM is to a degree that prominent Iranian scientist and physician, Razi (854-921 AD), says: "as long as you can use foods for curing diseases, avoid from pharmaceuticals, and use simple materia medica as long as not being forced of using multi-ingredient pharmaceuticals" [17], Given that chronic diseases have been causing problems in all societies in the world, the World Health Organization (WHO) reported that chronic diseases are one of the most important causes of early death, for example, diabetes is a chronic disease that gradually develops in patients who are prone to kidney problems. Ethnic and traditional FF-based treatments not only can prevent and control chronic diseases without showing side effects of synthetic pharmaceuticals in humans, but also do not cause obesity, neurological problems, and cardiovascular disease [18]. Here, Bavi as a pure Iranian tribe, which is rich in folk medicine and FF experiences, is the subject of the study.

\section{Bavi tribe}

Kohgiluyeh va Boyerahmad province, Iran, has special climate variation which has led to biodiversity of medicinal plants in this province. People of Bavi-one of the tribes who live in this province-have long enjoyed the benefits of traditional and ethnic medicine and their experiences in order to meet their medical needs. Many trial and errors in the treatment of diseases by indigenous healers have led to availability of reliable ethnic therapeutic regimens for patients. The ethnic medicine of Bavi tribe is extensive and contains different FFs that reveal the role of diet in prevention and treatment of diseases [19].

Bavi tribe area includes Basht and Gachsaran cities, located in the south of Kohgiluyeh va Boyerahmad, the lands of Choram in the north, Boyerahmad-e garmsir in the northwest and west, Rostam and Mamasani in the northeast and east, and Zohreh River in the south of the Bavi region (Fig. 1). Traditionally, the Bavi land is divided into two areas: Poshtkoh and Zirkoh. Poshtkoh includes Basht and Kohmara. Zirkoh includes Poshtband and Zirband. Poshtkoh areas are cold regions, while Zirkoh areas are tropical [20]. Bavi tribe consists of four great gens, Shaikh Jalil, Dolyari (Dolatyari), Alishi (Alishahi), and Gashin, and 15 small gens [20]. The traditional way of livelihood of Bavis is based on livestock, gardening, and agriculture. After oil exploration in the Bavi region and the expansion of oil facilities in Gachsaran, groups of these people got hired at oil companies. From 1976 AD, the urban population gradually increased (although no exact figures are available), and their economic activities became diverse. Now, Bavi tribe families, besides traditional agricultural and livestock activities, are also engaged in urban occupations [20]. 


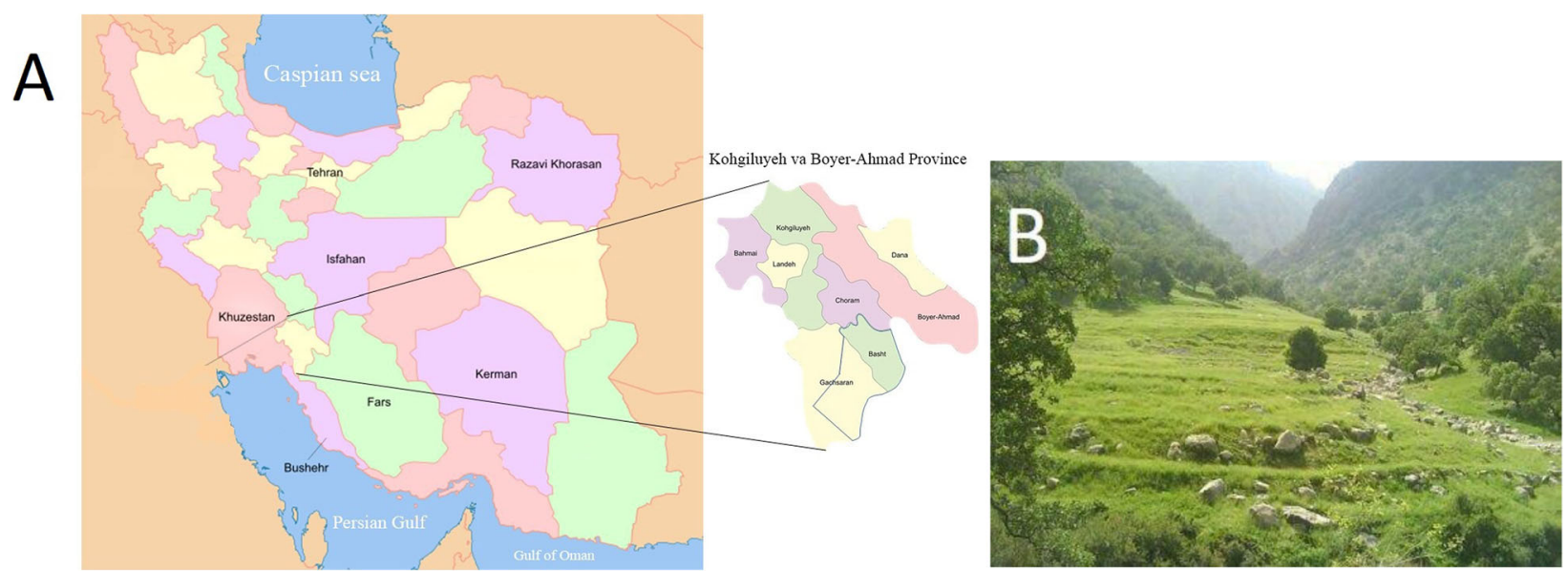

Fig. 1 a Location of Bavi tribe in Kohgiluyeh va Boyerahmad province (southwestern), Iran. All the people living in the town of Basht are originally from Bavi tribe, but part of them have been immigrated to Gachsaran in the last 50 years. b Bavi tribe nature. Khami Mountain separates Gachsaran and Basht city from each other. It is located at southwest of Basht and northeast of Gachsaran City, $3200 \mathrm{~m}$ high. The people of Bavi tribe live in the mentioned two cities and related villages around this mountain. The photo was taken by Mr. Ahmad Kamaei in the spring season

\section{Methods and materials}

\section{Data gathering and preparing functional foods}

For collecting information, local therapists were identified and interviewed from Bavi tribe's residence: Basht and Gachsaran regions in Kohgiluyeh va Boyerahmad province, Iran (30.16-30.77 N, 50.89-51.5 E) (Fig. 1). Of 11 interviewed therapists ( 7 males and 4 females), a therapist was from Shaikh Jalil gen, another one from Dolyari (Dolatyari) gen, also a therapist from Alishi (Alishahi) gen, 2 therapists were from Gashin gens, and 6 therapists were from small gens. Ten therapists did not have academic degree and a therapist had bachelor degree. The most abundant age range of participants in this study was 65-74 years old, which compromises $36 \%$ of the participants in the study. Here, 114 questions were asked in the form of open questionnaire. Questions were about the treatment of various diseases, maintaining body balance, and human health. Questions were asked from medical practitioners and local experts by an expert native researcher in the location areas of Bavi tribe (Fig. 2). The procedure of FF preparation was asked, and they were prepared again by a local expert by means of native tools and raw materials and ethnic procedures. Local FF preparation methods were recorded, and as an example, the preparation of Shole-e Bayomi tape video is included as the supplementary data.

\section{Plant materials}

Plant materials which are used in the FFs' formulations were collected and identified by our botanist: Sedigheh Khademian and voucher samples are kept in the Herbarium of Shiraz Faculty of Pharmacy.

\section{Categorization and literature review}

After collecting data, information about FFs were extracted and categorized into five groups: functional beverages, functional dairy products, functional halvas, functional soups, and functional stews. Local name, method of preparing, and therapeutic uses of the FFs, as well as information about herbals which is used for preparing FFs including plant's name, type, and part used

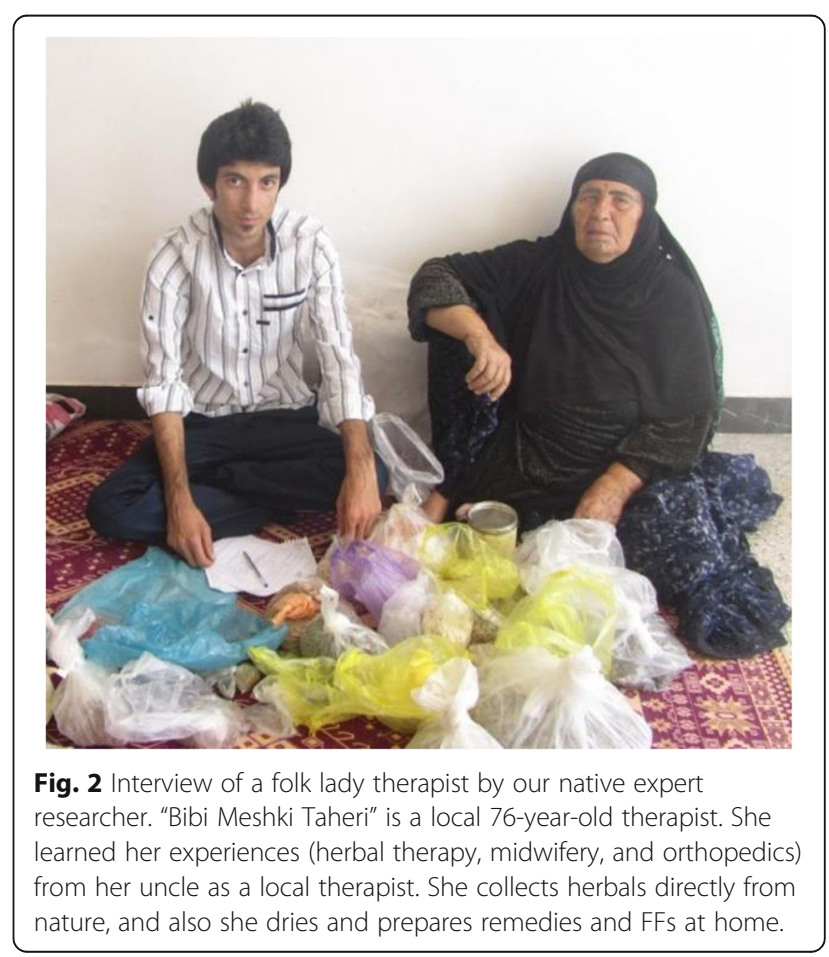


are included in Table 1. Literature review for herbal FFs' ingredients was performed based on articles indexed in Scopus, PubMed, and Google Scholar up to July 2018 and related texts.

\section{Results and discussion}

The climate conditions in Kohgiluyeh va Boyerahmad province (Iran) have led to growth of various medicinal plants. The cities Basht and Gachsaran, which are the residence fields of Bavi tribe, are located in this province. The deprivation of the area and the lack of access to physicians and midwives in the past have made local therapists able to take advantage of all the potential of nature and use herbal therapies and advising FFs for treatment. Many trials and errors in the treatment of illnesses by traditional physicians have led to the availability of reliable patient care regimens today [2].

\section{Historical, cultural, and social significance of Bavi tribe's FFs}

In minor ethnicities, most foods are used based on beliefs and rituals. Food-related customs appear to be the result of people's long-term contact, usage, and credence on their health properties. Below are the historical, cultural, and social characteristics of available Bavi tribe FFs.

Ghandaghak-e Khakshir: Given the scarcity of food sources in the past, it was enjoyable for people to intake sweet foods. In addition to giving Ghandaghak-e Khakshir to the patients, it also has been given to children who like sweets.

Ou-shireh: Mothers, especially in winter, give $\mathrm{Ou}$ shireh to children and patients as a snack between breakfast and lunch. Adults have good feelings about eating Ou-Shireh because of their memories and background from their childhood.

Doo va noon: This food is frequently used among Bavi tribe ranchers or farmers.

Kalg-o Mas: It is one of the historical Bavi's FFs in the tribe since this region is a rich habitant of oak trees as a source for Kalg (oak). This FF was mostly used in diseases without specific custom.

Mas-o Berenjas-o Darameh: Basically, plant vegetation and people's occupation are determinants of food preparing style [32]. Berenjs (Achillea santolinoides) and Darameh (Artemisia sieberi) are mostly grown in the cold regions of Bavi's tribe. Therefore, their fresh plant materials are attractive for cold boundary people, while dried plants are used for food preparing in tropical regions.

Mas-e Toleii: This is one of the locals' favorite foods. Because of popularity, nowadays, Tola (Malva sylvestris) is frozen and used for not growing seasons of the plant.

Shol-e Shiri: This food is used by Bavi tribe in happy ceremonies and family gatherings in cold seasons.
Mother of the family usually cooks this nostalgic food for the whole family.

Gelafteh: It is also one of the most nostalgic foods which is mostly cooked for celebrations.

Doo va Kardeh: Kardeh (Arum rupicola) grows mostly in the high and cold regions, and it is collected by local people in winter. The mother of the family starts preparing Doo va Kardeh as an attractive FF from the previous night, and normally, it is ready around 4 a.m. as a breakfast. Because of difficulties in preparing, neighbors often make turns in preparation and gifting the food to each other.

Shol-e Bayomi: Given that this food contains bitter almond (Bayom) which is an abundant tree in the mountains of Bavi tribe region, people can easily prepare it. Shepherds as almond collectors pick fruits of the tree while grazing sheep.

\section{Medicinal and healthcare properties of Bavi tribe's FFs} In this research, after collecting information about all common ethnic medicines used in Bavi tribe, 21 FF formulations were collected and presented in Table 1. Naming of Bavi tribe FFs is usually based on their ingredients. In some cases of FFs, the first part of the name reflects the form of that food. For instance, "Shole" in "Shole-e Shiri" or "Sholee Bayomi" means soup, while sometimes the word which is used at the beginning of the name of the food indicates the importance of that FF, i.e., "Dova" (means medicine) indicates that FF's role for medicinal purposes. Such naming of FF reflects powerful cultural beliefs and background of the Bavi tribe.

According to the food preparation method, Bavi's FFs may be categorized into eight functional dairy products, seven functional soups, five functional beverages, a functional halva, and a functional stew. Bavi tribe FFs usually contain high levels of primary metabolites as the food basis, e.g., carbohydrates, proteins, vegetable acids, oils, or lipid ingredients in the form of rice, flour, sugar, milk, or fruit juices. For instance, FF dairy products (Table 1) are rich in lipids and proteins, while FF soups are rich in carbohydrates, proteins, or lipids. The similarity of such food-based medicines with common foods like cooking process $(62 \%$ here), taste and smell, can be factors that affect appetite and compliance of patients. The second part of FFs in most cases is a medicinal plant which is responsible for FF action, e.g., Quercus brantii in Kalg-o Mas or Malva sylvestris in Mas-e toleii in Bavi tribe. Plants are the most important source of FFs and pharmaceuticals of ethnic groups [33-35]. In this study, we have made all Bavi formulation again according to native recipe using local tools. Most of the tools are wooden and can be made easily, and also herbal sources are abundant and available in Bavi living place. 


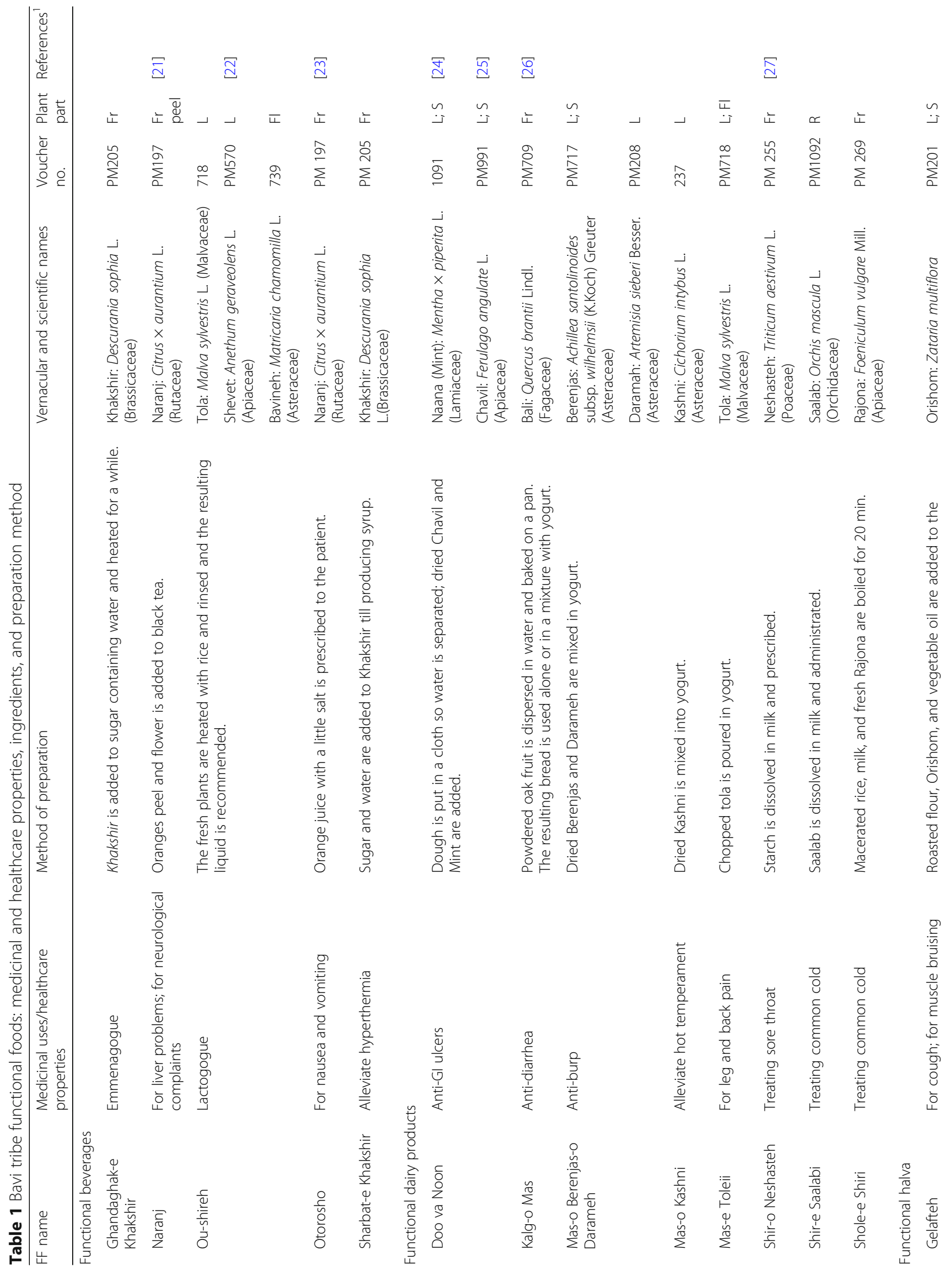




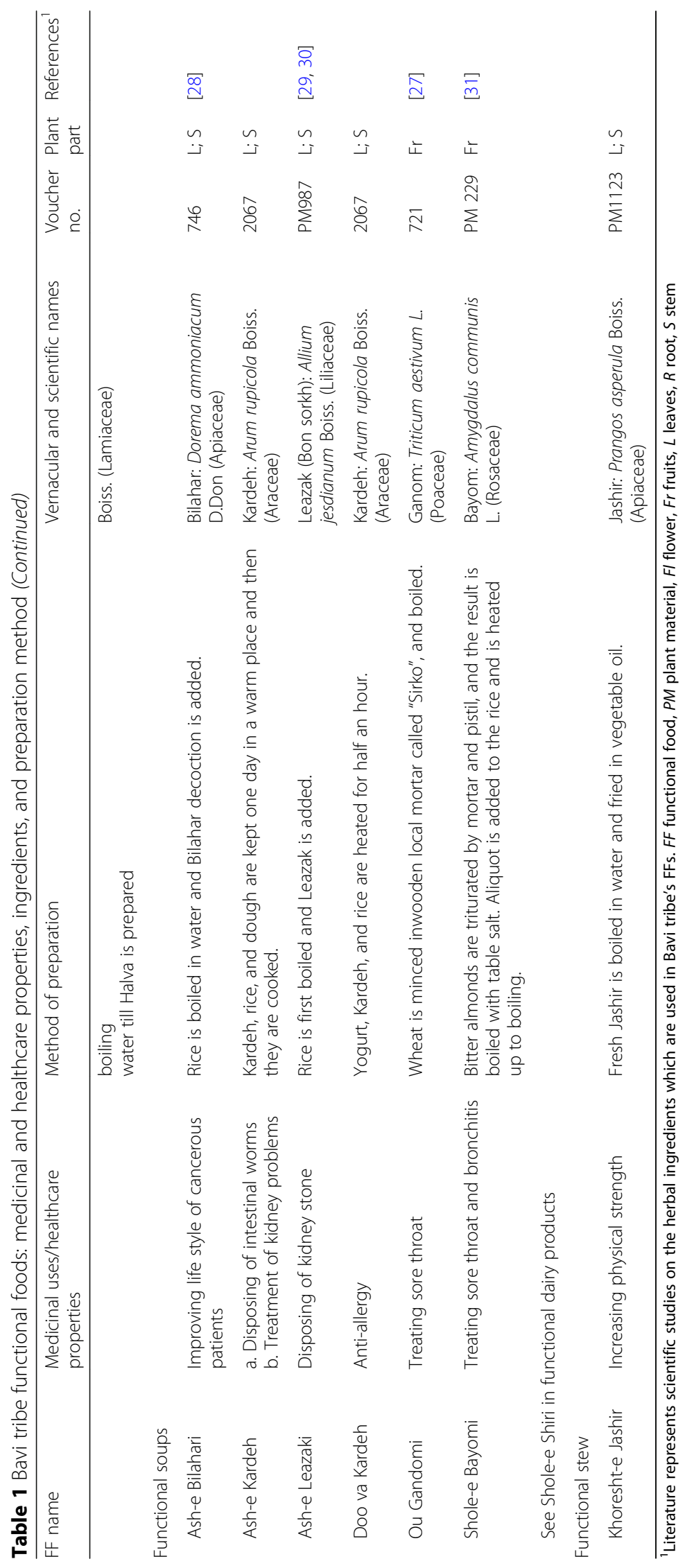


The results showed (Fig. 3) that most FFs are used to treat chronic proposes $(57 \%)$ including kidney problems like kidney stones, liver disease, neurological complaints, and GI ulcers and are used as lactogogue, while lesser FFs are used to treat acute diseases and symptoms (43\%), including nausea and vomiting, common cold, diarrhea, sore throat, and allergy. This highlights the importance of natural resources for treating chronic ailments.

There are similarities between FFs usage and Bavi tribe with other parts of Iran, and literature supports action of some medicinal plants that is prominent in Bavi FFs. For example, it is reported that oral administration of Naranj peel can alleviate liver disease due to lowering cholesterol levels [21] that confirm its ethnic usage as liver drug. Moreover, it is reported that Anethum geraveolens $\mathrm{L}$. as a medicinal plant ingredient of $\mathrm{Ou}$ Shireh is responsible for milk production in nursing mothers [22]. The use of Menthaxpiperita L. and Ferulago angulate L. in "Doo va Noon" as anti-GI ulcers can be supported by the results which show the effect of Menthaxpiperita L. on gastric ulcers [24] and Ferulago angulate L. as a treatment for chronic stomach ulcers [25]. The astringency of oak powder cases show that some tribesmen and villagers in Kohgiluyeh va Boyerahmad province eat a mixture of honey and oak powder before breakfast for treating ulcer [36]. Tannin content would be responsible for oak [26] containing FFs anti-diarrhea effects, in

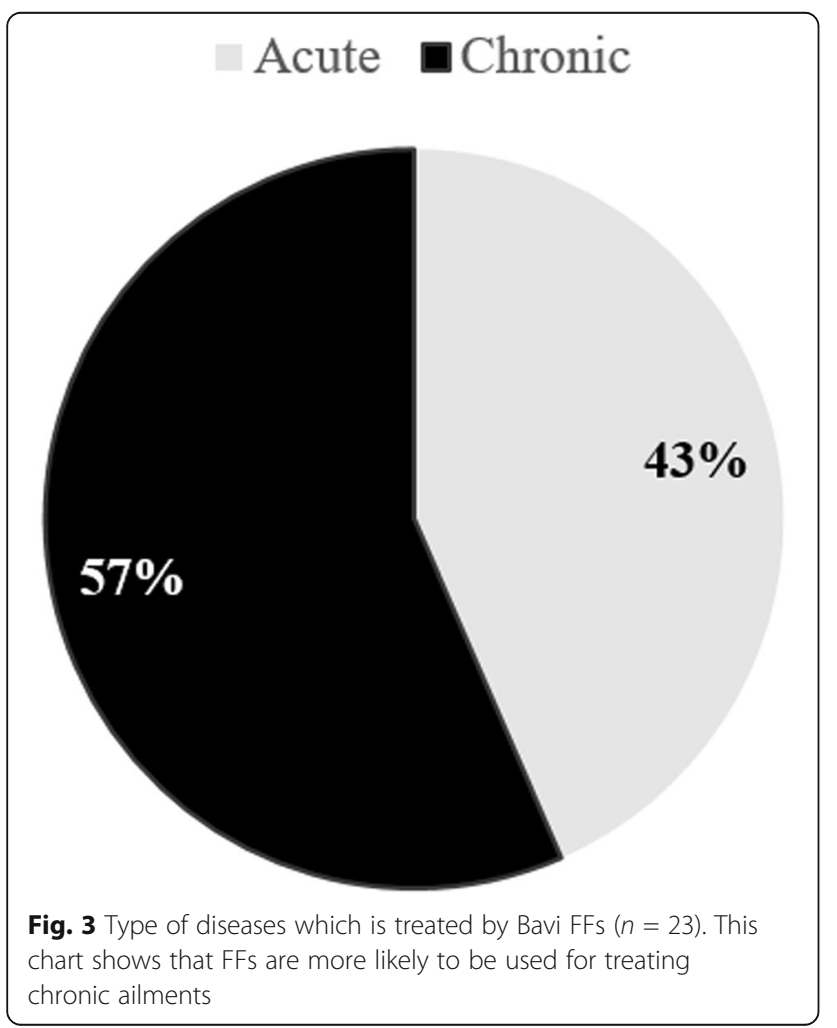

which their products are common in ethnic culture of the Bavi tribe. People of Bavi tribe use Shir-o Neshasteh as well as $\mathrm{Ou}$ Gandomi which are made from wheat (Triticum aestivum L.) for sore throat. Similarly, in areas of Meybod city (Yazd province), traditional FFs called "Harireh" and "Ferni" (cooked with milk and rice flour), hot liquids, pistachio, starch, and sugar are used for treating sore throats [30]. A similar effect of using $T$. aestivum extraction as a mouthwash for treating sore throat is reported in the literature [27]. Ash-e Bilahari is one of the ethnic foods from Bavi tribe which is presented for improving life style of cancerous patients. Cytotoxic effect of Dorema ammoniacum D. Don as the main medicinal plant constituents in Ash-e Bilahari is reported earlier [28]. It is reported that Allium jesdianum Boiss. in Ash-e Leazaki FF is used as a disposing urethral stones agent, and when it is added to the patient's diet, it increases the rate of stone disposition [29]. Finally, the people of Bavi tribe use Shole-e Bayomi as a treatment for sore throat and bronchitis. Based on recent researches, antimicrobial property of bitter almond as an active ingredient of this FF has been reported [31], which supports the ethnic belief. Many researches showed that the pharmacological effects of FFs are the main reason of their consumption [37-39]. However, in some studies, it has been reported that the use of medication or food can be based on local people's beliefs [3].

\section{Medicinal plant constituents of Bavi tribe FFs}

According to Table 1, 20 plant species from 12 plant families are used as active raw materials in Bavi tribe FFs. Among them, Apiaceae (25\%), Asteraceae (20\%), and Lamiaceae $(10 \%)$ families are the most common families (Fig. 4). Figure 4 shows that most of the plants (80\%) which are used in FFs of Bavi tribe are perennials. Also, our results show that most plants used in FFs of Bavi tribe diets are wild growing (70\%) compare with cultivated plants (20\%), which may be related to the nomadic lifestyle of the tribe. Furthermore, the most commonly used plant parts in the Bavi tribe FFs are leaves with a frequency of $41 \%$ and stems with an abundance of $28 \%$ (Fig. 4). Significant share of leaves, fruits, flowers, and stems (97\%) in the preparation of a large number of FFs of Bavi tribe compared with underground organs $(3 \%)$ indicates native tendency for saving plants and using mainly renewable plant organs.

Figure 4 shows that most of the Bavi tribe FFs are produced from plants containing aromas (75\%). In other words, in the Bavi tribe, natives use aromatic plants probably not only because of their health benefits but also as a condiment for improving FF flavor. Although some studies indicate that organoleptic characteristics of FF is not significantly effective in FF acceptance [40, 41], others have reported that organoleptic characteristics of FFs, including aroma, can be effective in determining how people tend to 


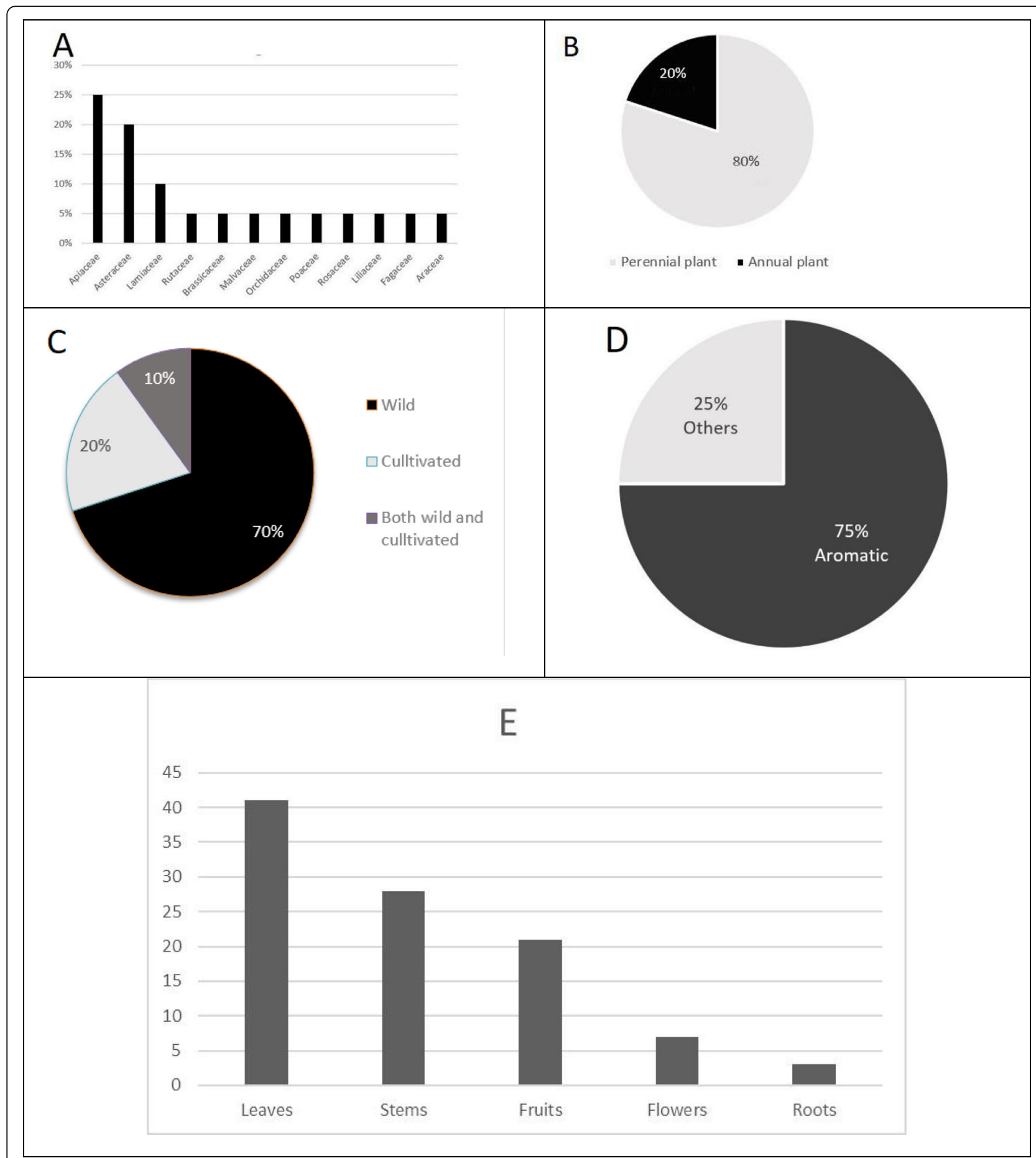

Fig. 4 Characterization of medicinal plant ingredients of Bavi tribe's FFs $(n=20)$. a Plant families, $\mathbf{b}$ plant types, $\mathbf{c}$ plant sources, $\mathbf{d}$ aromatic versus non-aromatic plants, e plant organs $(n=29)$

consume those FFs [42]. In addition, from an ethnopharmacological view, taste is a key factor in indigenous FF selection, e.g., selecting bitter herbals for treat diabetes [34, 35]. Although it is difficult to determine human food behaviors, it is reported that specific characters, including social background, consumer demographic information, trusting, personal motivation, health awareness, and their attitude to pharmaceuticals, may play an important role in human acceptance [43-45]. Such factors may be involved in the attraction and keeping tradition of preparing FFs for health and treatment among a native tribe like Bavi. Moreover, such ethnic FFs probably psychologically motivate people 
to get a better medical outcome due to their historical backgrounds and simultaneous consumption of foods in a family gathering [46].

\section{Conclusion}

FFs from native sources like the Bavi tribe should present new opportunities for healthcare and treatment. In order to analyze native behaviors in choosing, consuming, and getting greater confidence to FFs, many factors should be reviewed, i.e., continuous contact with wild and perennial plant materials of FFs in the living field; accompanying family with patient during preparing, cooking period, and eating like a meal; probable dialogue on previous generations beliefs about beneficial effects of that FF; organoleptic food properties of FFs like aroma, taste, and appearance; and do not have unpleasant feelings of pharmaceutical dosage forms like injection because of food-like oral taking. "Memorial FFs" might be a suggesting term for ethnic FFs, since it triggers nostalgic and/or pleasurable memory revival in patients. This memory background might elicit better patients' compliance and/or better therapeutic output eventually. All in all, further study of ethnopharmacological aspects of native behaviors linked to psychological considerations would be the result in a new interdisciplinary opportunity for healthcare and curing.

\section{Abbreviations}

FF: Functional food; TPM: Traditional Persian medicine; WHO: World Health Organization

\section{Acknowledgements}

We thank the Shiraz University of Medical Sciences for their financial support (grant no: 98-01-36-21536), people of the Bavi tribe because of their excellent cooperation, and Eshrat Askari for her cooperation in preparation of FFs.

\section{Authors' contributions}

EA wrote the manuscript and designed the diagrams. AM designed the research and supervised the study. HA interpreted the data, performed the survey, and made the photographic documentation. All authors read and approved the final manuscript.

\section{Funding}

This article was written with the financial support of the Shiraz University of Medical Sciences, Iran, using the Pharm.D thesis of H.A.

\section{Availability of data and materials}

The data that support the findings of this study are available from the corresponding author, prof. Abdolali Mohagheghzadeh, upon reasonable request.

\section{Competing interests}

The authors declare that they have no competing interests.

\section{Author details}

'Department of Phytopharmaceuticals (Traditional Pharmacy), Faculty of Pharmacy, Shiraz University of Medical Sciences, P. O. Box 1583, 71345 Karafarin Avenue, Shiraz, Iran. ${ }^{2}$ Student Research Committee, Shiraz University of Medical Sciences, Shiraz, Iran. ${ }^{3}$ Pharmaceutical Sciences Research Center, Shiraz University of Medical Sciences, Shiraz, Iran.
Received: 5 October 2019 Accepted: 6 February 2020

Published online: 25 March 2020

\section{References}

1. Esfahani M, Zolfaghari B, Karimi H, Ghannadi A. Traditional Iranian medicine a valuable source to introduce medicinal \& functional foods. J Islamic Iran Trad Med. 2012;3(1):77-94

2. Ghannadi A, Zolfaghari B, Shamashian S. Necessity, importance, and applications of traditional medicine knowledge in different nations. J Islamic Iran Trad Med. 2011;2(2):161-76.

3. Jennings HM, Merrell J, Thompson JL, Heinrich M. Food or medicine? The food-medicine interface in households in Sylhet. J Ethnopharmacol. 2015; 167:97-104.

4. Mahan LK, Escott-Stump S, Raymond JL, Krause MV. Krause's food \& the nutrition care process: Elsevier Health Sciences; 2012.

5. Action E. Scientific concepts of functional foods in Europe: consensus document. Brit J Nutr. 1999:81(1):1-27.

6. Visioli F, Grande S, Bogani P, Galli C. The role of antioxidants in the Mediterranean diets: focus on cancer. Eur J Cancer Prev. 2004;13(4):337-43.

7. Jacka FN, Pasco JA, Mykletun A, Williams LJ, Hodge AM, O'Reilly SL, et al. Association of Western and traditional diets with depression and anxiety in women. Am J Psychiatr. 2010;167(3):305-11.

8. McMartin SE, Jacka FN, Colman I. The association between fruit and vegetable consumption and mental health disorders: evidence from five waves of a national survey of Canadians. Prev Med. 2013;56(3-4):225-30.

9. Esposito E, Rotilio D, Di Matteo V, Di Giulio C, Cacchio M, Algeri S. A review of specific dietary antioxidants and the effects on biochemical mechanisms related to neurodegenerative processes. Neurobiol Aging. 2002;23(5):719-35.

10. Aruoma OI, Bahorun T, Jen L-S. Neuroprotection by bioactive components in medicinal and food plant extracts. Mutat Res. 2003;544(2-3):203-15.

11. Ferrari CK. Functional foods, herbs and nutraceuticals: towards biochemical mechanisms of healthy aging. Biogerontology. 2004;5(5):275-89.

12. Iriti M, Vitalini S, Fico G, Faoro F. Neuroprotective herbs and foods from different traditional medicines and diets. Molecules. 2010;15(5):3517-55.

13. Krystallis A, Maglaras G, Mamalis S. Motivations and cognitive structures of consumers in their purchasing of functional foods. Food Qual Prefer. 2008; 19(6):525-38.

14. Kaur N, Singh DP. RETRACTED: Deciphering the consumer behaviour facets of functional foods: a literature review: Elsevier; 2017.

15. Menrad K. Market and marketing of functional food in Europe. J Food Eng. 2003;56(2-3):181-8.

16. Menezes E, Deliza R, Chan HL, Guinard J-X. Preferences and attitudes towards açaí-based products among North American consumers. Food Res Int. 2011;44(7):1997-2008.

17. Naseri M. An overview of the generalities of traditional medicine in Iran Tehran: Iranian Traditional Medicine Publications. 1395:27.

18. Martirosyan DM. Functional foods for chronic diseases: D\&A Inc; 2006.

19. Askari H. Data collection of folk and traditional medicine of Bavi tribe and consolidation of in vitro four selected sample (Pharm.D. thesis); 2012.

20. M B. Kuhgiluyeh and its tribes. Shiraz: Navid-e Shiraz. 2013.

21. Milind P, Dev C. Orange: range of benefits. Int Res J Pharm. 2012;3(7):59-63.

22. Jana S, Shekhawat G. Anethum graveolens: an Indian traditional medicinal herb and spice. Pharmacog Rev. 2010:4(8):179.

23. Fathi H, Mohammad Shahi N, Latifi A, Zamani A, Shaki F. Evaluation of antiemetic effect of metabolic, aesthetic and aqueous extracts of Citrus aurantium L. on chicken. J Gorgan Univ Med Sci. 2016;18(3):34-9.

24. BWP DAB, Consultation E, BWP AB, CHMP AB. European medicines agency evaluation of medicines for human use. 2006.

25. Shahneh FZ, Valiyari S, Azadmehr A, Hajiaghaee R, Bandehagh A, Baradaran B. Cytotoxic activities of Ferulago angulata extract on human leukemia and lymphoma cells by induction of apoptosis. J Med Plants Res. 2013;7(1 1):677-82.

26. Kaur G, Hamid H, Ali A, Alam MS, Athar M. Antiinflammatory evaluation of alcoholic extract of galls of Quercus infectoria. J Ethnopharmacol. 2004;90(23):285-92.

27. Polshettiwar S, Khorate SS. Triticum aestivum-a green gold. World J Pharm Pharmaceut Sci. 2016:5(4):636 651.

28. Ghavamizadeh M, Mohammadi J, Mirzaei A, Sadegh H, Akbartabar M. Cytotoxicity of Dorema auchri, Achillea millefolium and Artemisia aucheri by Artemia urmiana brine shrimp lethality test (BSLT); 2013.

29. Ghilichkhani M. Evaluation of the effect of Allium jesdianum on the rate of urinary excretion: Arak; 2013. 
30. Janebollahi M. Ethnographic look at traditional and ethno medicine of Iranians. Tehran: Amirkabir Publication; 2011.

31. Tian H, Zhang H, Zhan P, Tian F. Composition and antioxidant and antimicrobial activities of white apricot almond (Amygdalus communis L.) oil. Eur J Lipid Sci Technol. 2011;113(9):1138-44.

32. Shisanya CA. Determinants of sustainable utilization of plant resources in the former Kakamega District. Kenya: African Books Collective; 2011.

33. Sandhu DS, Heinrich M. The use of health foods, spices and other botanicals in the Sikh community in London. Phytother Res. 2005;19(7):633-42.

34. Pieroni A, Torry B. Does the taste matter? Taste and medicinal perceptions associated with five selected herbal drugs among three ethnic groups in West Yorkshire, Northern England. J Ethnobiol Ethnomed. 2007;3(1):21.

35. Pieroni A, Zaman H, Ayub S, Torry B. My doctor doesn't understand why I use them. Herbal and Food Medicines Amongst the Bangladeshi Community in West Yorkshire, UK: 2010. p. 112-46.

36. Foroughi $\mathrm{H}$. The importance of indigenous knowledge in the use of medicinal plants in the nomadic regions of Kohgiluyeh va Boyerahmad province. Karaj: Agricultural Education; 2007.

37. Etkin NL, Ross PJ. Food as medicine and medicine as food: an adaptive framework for the interpretation of plant utilization among the Hausa of northern Nigeria. Soc Sci Med. 1982;16(17):1559-73.

38. Pieroni A, Quave CL. Functional foods or food medicines? On the consumption of wild plants among Albanians and southern Italians in Lucania. Eating Healing Trad Food Med. 2006:101-29.

39. Prendergast HD, Etkin N, Harris D, Houghton P. Plants for food and medicine. Proceedings of the joint conference of the Society for Economic Botany and the International Society for Ethnopharmacology, London, UK, 1-6 July 1996. Kew: Royal Botanic Gardens; 1998.

40. Augustin M. Functional foods: an adventure in food formulation; 2001

41. Drewnowski A. Taste preferences and food intake. Ann Rev Nutr. 1997;17(1): 237-53.

42. Wilson DW, Nash P, Buttar HS, Griffiths K, Singh R, De Meester F, et al. The role of food antioxidants, benefits of functional foods, and influence of feeding habits on the health of the older person: an overview. Antioxidants. 2017;6(4):81.

43. Büyükkaragöz A, Bas M, Sağlam D, Cengiz ŞE. Consumers' awareness, acceptance and attitudes towards functional foods in T urkey. Int I Consum Stud. 2014;38(6):628-35.

44. Vecchio R, Van Loo EJ, Annunziata A. Consumers' willingness to pay for conventional, organic and functional yogurt: evidence from experimental auctions. Int J Consum Stud. 2016;40(3):368-78.

45. Brečić $\mathrm{R}$, Gorton $\mathrm{M}$, Barjolle $\mathrm{D}$. Understanding variations in the consumption of functional foods-evidence from Croatia. Br Food J. 2014

46. Verbeke W. Consumer acceptance of functional foods: socio-demographic, cognitive and attitudinal determinants. Food Qual Prefer. 2005;16(1):45-57.

\section{Publisher's Note}

Springer Nature remains neutral with regard to jurisdictional claims in published maps and institutional affiliations.

Ready to submit your research? Choose BMC and benefit from:

- fast, convenient online submission

- thorough peer review by experienced researchers in your field

- rapid publication on acceptance

- support for research data, including large and complex data types

- gold Open Access which fosters wider collaboration and increased citations

- maximum visibility for your research: over $100 \mathrm{M}$ website views per year

At BMC, research is always in progress.

Learn more biomedcentral.com/submissions 